\title{
Chaperone DnaJ Influences the Formation of Biofilm by Escherichia coli
}

\author{
ANNA M. GRUDNIAK*, JOLANTA WŁODKOWSKA and KRYSTYNA I. WOLSKA \\ Department of Bacterial Genetics, Institute of Microbiology, Faculty of Biology, University of Warsaw, Poland
}

Submitted 11 February 2015, Revised 16 July 2015, Accepted 17 July 2015

\begin{abstract}
DnaJ chaperone, a member of the so called DnaK-DnaJ-GrpE chaperone machine plays an important role in cell physiology. The ability of Escherichia coli $\Delta d n a J$ mutant to form biofilm was studied. It was shown that this mutant is impaired in biofilm development when exposed to $42^{\circ} \mathrm{C}$ for $2 \mathrm{~h}$. The impairment in biofilm development was observed when the heat shock was applied either at the onset of biofilm formation or $2 \mathrm{~h}$ later. The biofilm formed was thinner and its structure was changed as compared to wild-type strain. This defect could be complemented by the introduction of a wild-type gene on a low-copy plasmid.
\end{abstract}

Key words: Escherichia coli, chaperone DnaJ, biofilm

In natural habitats the majority of microbes form a structured biofilm ecosystem in which bacterial communities are embedded in an extracellular polymeric matrix which stabilizes biofilm structure and mediates bacterial adhesion (Flemming and Wingender, 2010). Bacterial biofilms can develop on various surfaces (Donlan, 2002) including every niche of the human body (Karatan and Watnick, 2009). Bacteria, including pathogens, when living in a biofilm, exhibit increased resistance to antimicrobials which creates a big medical problem (Hoiby et al., 2010). The formation of an E. coli biofilm requires several factors including fimbriae, adhesins, polysaccharides, lipopolysaccharides, small signaling and quorum sensing molecules (Beloin et al., 2008). Biofilms formed by pathogenic strains cause several food and water-born diseases such as diarrhea, urinary tract infections and chronic bacterial prostatitis (McFarlane and Dillon, 2007).

DnaJ chaperone is a prototypical member of the Hsp40 family and functions as a cochaperone of DnaK (Hsp70). It contains distinct domains involved in the regulation of the activity of Hsp70 and the binding of several substrates with different conformational properties - folded, partially (un)folded and unfolded (Walsh etal., 2004). The main function of DnaJ and DnaK is assistance in the folding of newly synthesized or unfolded polypeptides. The interaction of DnaJ with the hydrophobic motifs of the substrate proteins modifies their structure and function, this being crucial for DnaJ-mediated transfer of substrates to Hsp70 and modulation of its ATPase activity (Cuéllar et al., 2013). The two-chaperone system is sufficiently versatile to act on the entire proteome and every protein is predicted to contain multiple DnaK and DnaJ-binding sites (Srinivasan et al., 2012). Recently it was demonstrated that DnaJ together with DnaK and Trigger Factor (TF) are strongly involved in protein translocation by their targeting to Sec and twin-arginine translocation (Tat) pathways (Castanié-Cornet et al., 2014).

The involvement of DnaK chaperone in bacterial biofilm formation is the subject of several papers (e.g. van der Veen and Abee, 2010) but there is only one publication describing an indirect effect of DnaJ on the development of Pseudomonas putida biofilms (Dubern et al., 2005). Therefore we decided to determine the importance of DnaJ for E. coli biofilm development by studying the ability of a dnaJ null mutant to form a biofilm. We also checked the effect of DnaJ on biofilm structure as well as cell viability and motility.

E. coli $\Delta d n a J$ strain (KW69) used in this study is a derivative of E. coli MC1061 (Casadaban and Cohen, 1980) in which dnaJ gene is replaced by $\mathrm{Kan}^{\mathrm{R}}$ cassette. To complement dnaJ deletion defect KW87 strain was constructed. Wild type dnaJ allel was introduced in pJW14 plasmid containing the replication origin of pACYC184 and carrying a chloramphenicol resistance determinant. The details of strain and plasmid genotypes and genetic manipulation procedures were described previously (Wolska et al., 2000). Strains were grown in LB medium supplemented with kanamycin to

\footnotetext{
* Corresponding author: A.M. Grudniak, Institute of Microbiology, University of Warsaw, Warsaw, Poland; e-mail: grudam@biol. uw.edu.pl
} 
final concentration of $100 \mu \mathrm{g} / \mathrm{ml}$ and glucose to final concentration $0.4 \%$. When necessary the medium was solidified with $1.5 \%$ agar and supplemented with chloramphenicol to final concentration $20 \mu \mathrm{g} / \mathrm{ml}$. To study bacterial motility LB medium solidified with $0.3 \%$ or $0.5 \%$ agar was used. The cultures of all strains were subjected to heat shock by transient elevation of temperature from $30^{\circ} \mathrm{C}$ to $42^{\circ} \mathrm{C}$ for $2 \mathrm{~h}$, control cultures were incubated constantly at $30^{\circ} \mathrm{C}$.

To determine the ability of MC1061, KW69 and KW87 strains to form a biofilm the following incubation protocol was used. Overnight cultures were diluted 100 -fold in LB medium with $0.4 \%$ glucose, incubated in polystyrene microtiter plates at $30^{\circ} \mathrm{C}$ for $2 \mathrm{~h}$, subjected to heat shock at $42^{\circ} \mathrm{C}$ for $2 \mathrm{~h}$ and incubated further at $30^{\circ} \mathrm{C}$ for additional $20 \mathrm{~h}$. The control cultures were incubated at $30^{\circ} \mathrm{C}$ for $24 \mathrm{~h}$. The amount of biofilm formed was determined after staining with crystal violet according to the procedure described by O'Toole and Kotler (1998). The absorbance at $570 \mathrm{~nm}$ was measured using microtiter plate reader (Sunrise, Tecan, Switzerland). To study the viability of cells biofilms formed in the condition described above were dried (by $20 \mathrm{~min}$ at $37^{\circ} \mathrm{C}$ ) and than $100 \mu \mathrm{l}$ of BacTiter$\mathrm{Glo}^{\mathrm{TM}}$ Reagent was added to each microplate well. After incubation for $5 \mathrm{~min}$ the luminescence was measured in Microplate Luminometr GloMax-Multi ${ }^{\circledast}$ Detection system (Promega, Madison, USA), using integration time $5 \mathrm{sec}$. The results are presented as a number of RLU (Relative Luminescence Units) (Hall et al., 1998; Lundin and Thore, 1975; https://pl.promega. com/resources/protocols/technical-bulletins/101/ bactiter-glo-microbial-cell-viability-assay-protocol/).

Bacterial motility was estimated according to the protocol described by Lippolis et al. (2014). Each experiment was performed 3 times. The photographs were taken at a fixed distance between the plates and camera.

SCLM (Confocal Laser Scanning Microscopy) was used to quantify biofilm development on the glass bottom of microscope dishes (WillCo Wells BV, the Netherlands, diameter $40 \mathrm{~mm}$, thickness of a glass bottom $0.16-0.19 \mathrm{~mm}$ ). The details of procedures were described previously by Raczkowska et al. (2011). SCLM was conducted using a Nikon Eclipse Ti (A1) microscope equipped with $\mathrm{a} \times 60,1.4 \mathrm{NA}$ oil immersion phase-contrast lens. An argon laser with a maximum emission line at $488 \mathrm{~nm}$ was used as the excitation source. Horizontal optical thin sections were collected at $4.0-\mu \mathrm{m}$ intervals from the outer surface of the biofilm to the bottom of the glass plate. These images were captured by NIS-ELEMENTS interactive software and three-dimensional reconstructions (3D) were created.

The data presented in Figure 1 show that $\Delta d n a J$ mutant strain is impaired in biofilm formation only in cultures transiently incubated at elevated temperature.

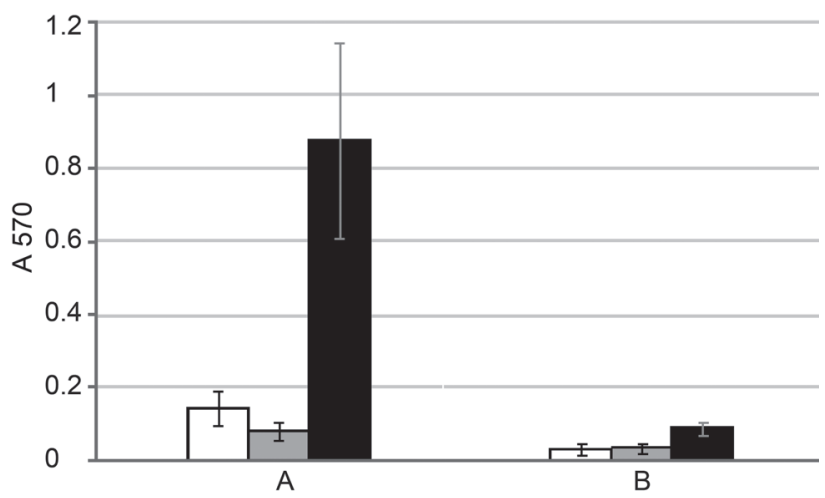

Fig. 1. The amount of biofilm formed by wild-type (white bars), $\Delta d n a J$ (grey bars) and complemented strains (black bars). Heat shock condition (A), and control condition (B).

The amount of biofilm formed was diminished nearly 2 -fold. It should be noted that raising the temperature for $2 \mathrm{~h}$ did not influence growth of $\Delta d n a J$, this effect is not observed until $3 \mathrm{~h}$ incubation at restrictive temperature (Paciorek et al., 1997). Complemented strain KW79 formed a 6.2-fold and 2.7-fold thicker biofilm than that formed by the wild type strain incubated with or without heat shock, respectively. It was also noted that the elevation of temperature is a factor severely inducing biofilm formation in all strains tested. This observation is consistent with the literature data mentioning that bacterial biofilm development can be considered a multicellular adaptation to physical stress (de la Fuente-Núňnez et al., 2013).

The micrographs presented in Fig. 2 clearly demonstrate that the biofilm formed by $\Delta d n a J$ mutant subjected to heat shock is much thinner than that formed by control MC1061 strain. Moreover no bulges were seen which suggests the lack of sites indicating the position of the future mushroom-shape structures characteristic for mature biofilms of many bacterial species. BactoTiterGlo ${ }^{\mathrm{TM}}$ assay was applied to determine the number of viable cells. The intensity of the signal is proportional to the amount of ATP in the sample and therefore to the number of metabolically active cells. It was demonstrated that the number of living cells in the biofilm is not significantly influenced by the lack of DnaJ chaperone either after heat shock or in control cultures (Tab. I).

Table I

The effect of DnaJ protein on cell viability in biofilm

\begin{tabular}{|l|cc|}
\hline \multicolumn{1}{|c|}{ Strain } & Heat shock & RLU $\times 10^{5}$ \\
\hline \multirow{2}{*}{ MC1061 } & + & 6.5 \\
\cline { 2 - 3 } & - & 2.9 \\
\hline \multirow{2}{*}{ KW69 } & + & 8.0 \\
\cline { 2 - 3 } & - & 3.9 \\
\hline \multirow{2}{*}{ KW87 } & + & 16.5 \\
\cline { 2 - 3 } & - & 4.5 \\
\hline
\end{tabular}

RLU - Relative Luminescence Unitsf 

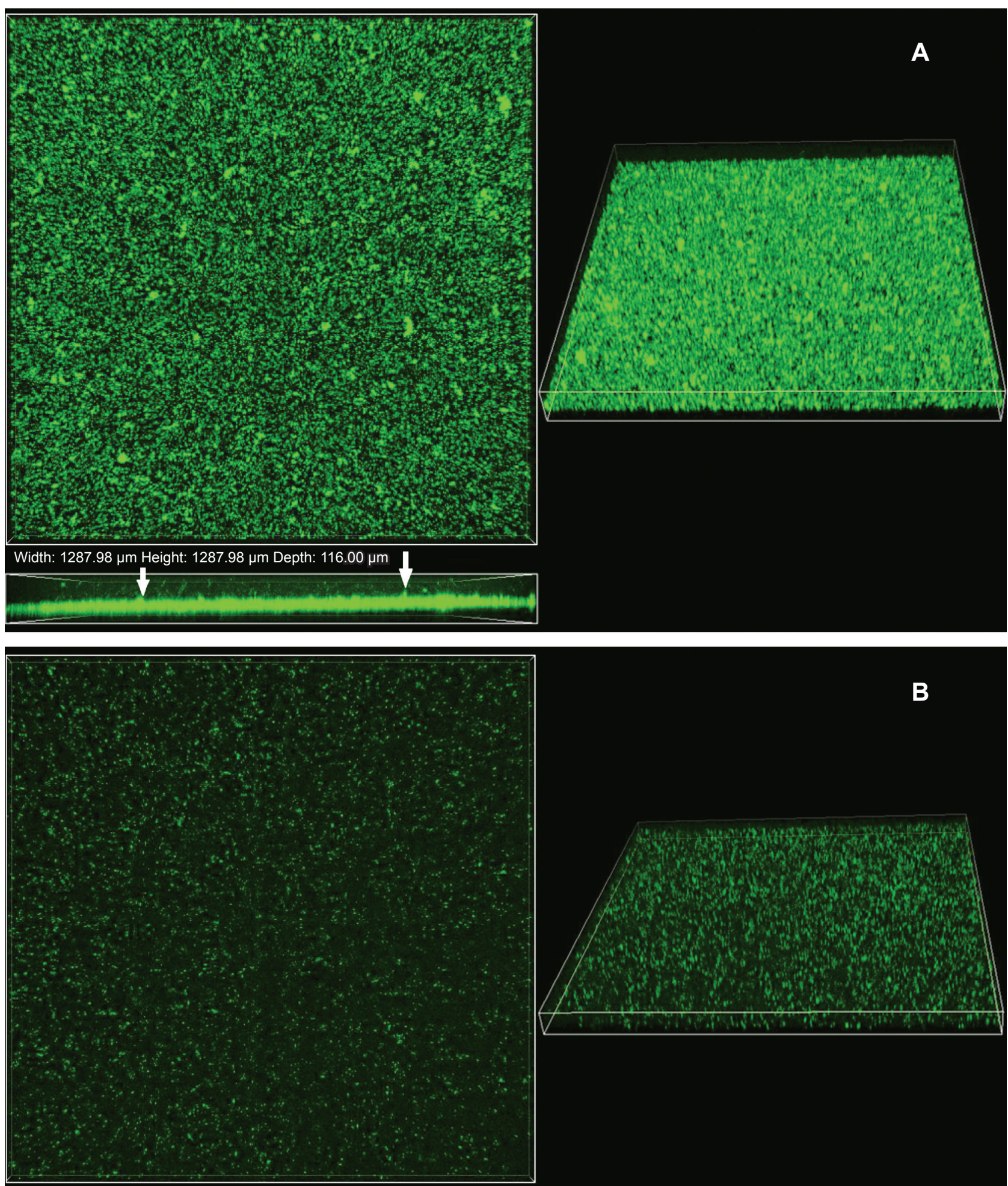

Width: $1287.98 \mu \mathrm{m}$ Height: $1287.98 \mu \mathrm{m}$ Depth: $72.00 \mu \mathrm{m}$

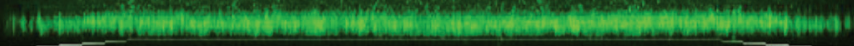

Fig. 2. Micrographs of E. coli biofilm after heat shock. Wild-type strain, control (A); $\Delta d n a J$ mutant (B). White arrows indicate the bulges in biofilm layer.

We also observed that in all strains tested heat shock resulted in the elevation of RLU what was consistent with the induction of biofilm formation. In complemented KW87 strain the increase of copy number of
dnaJ gene leads to an increase in the number of living cells in biofilm in comparison to wild type strain.

The involvement of DnaJ chaperone in Pseudomonas putida PCL1445 biofilm formation and degradation was 

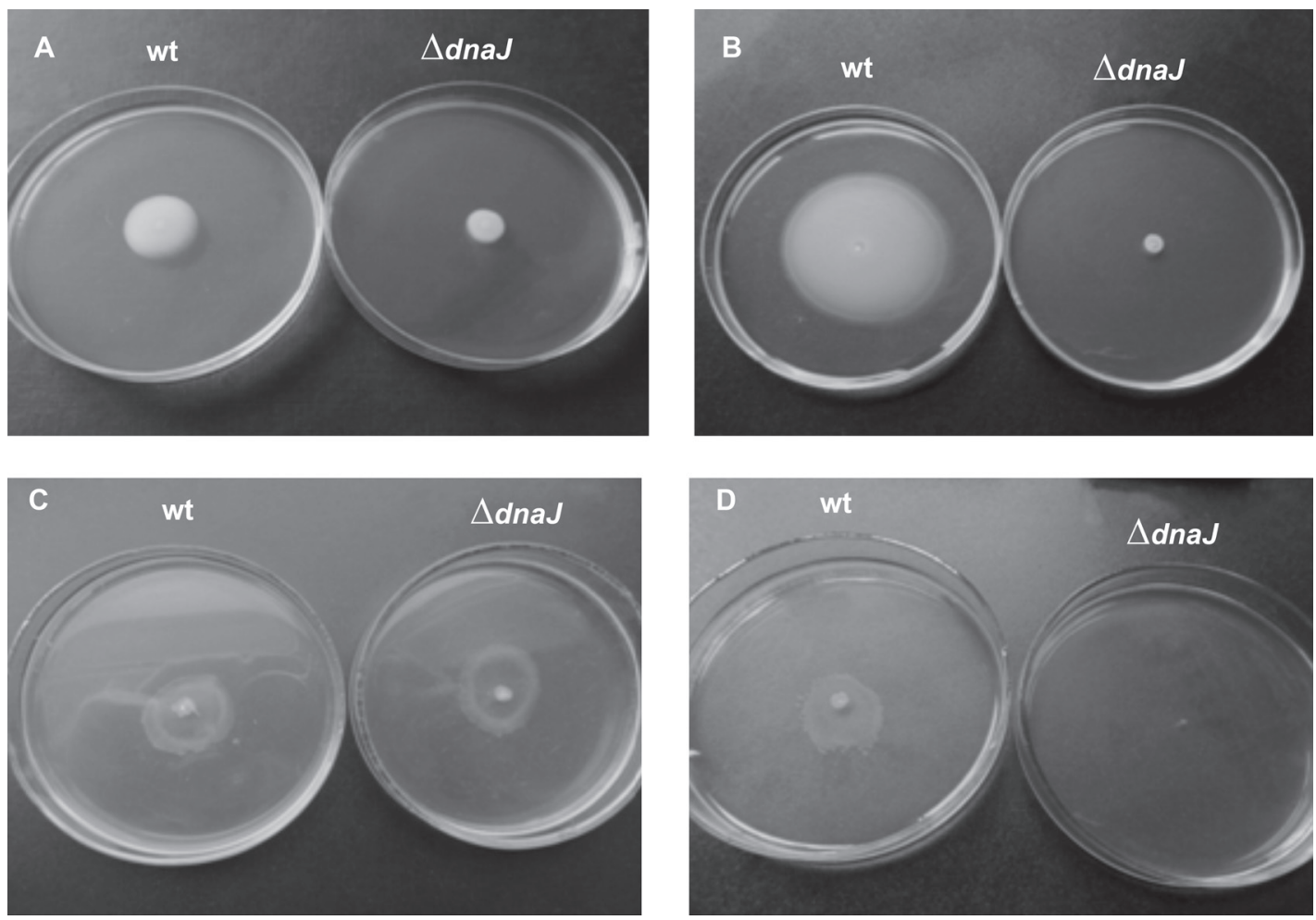

Fig. 3. Swimming and swarming motility. Swimming motility, control (A); swimming motility after heat shock (B); swarming motility, control (C); swarming motility, heat shock (D).

concluded by its involvement in the regulation of two cyclic lipopeptides, putisolvin I and II (Dubern et al., 2005). On the contrary, the role of partner chaperone DnaK in formation of Staphylococcus aureus and Streptococcus mutans biofilm has been well proven (Singh et al., 2012; Lemos et al., 2007). The role of DnaJ protein in formation of biofilm by E. coli has not been studied until now so the results of our experiments demonstrating that DnaJ chaperone is involved in biofilm development in this species have the virtue of originality.

The inhibition of biofilm was seen when the heat shock was applied after $2 \mathrm{~h}$ from the onset of biofilm formation or just at the beginning of experiment (data not shown), which suggests that extracellular matrix formation can be inhibited, for example by a defect in polysaccharide secretion. However, the early stages of biofilm development - such as adhesion utilizing type I pili, curli and conjugative pili and colonization of the surfaces cannot be excluded. Bacterial swimming motility is a factor severely influencing adhesion (Verstraeten et al., 2008). Swarming motility is a factor positively influencing biofilm formation (Verstraeten et al., 2008). Therefore the ability of $\Delta d n a J$ mutant to move in swimming and swarming fashion was checked. The inhibition of both types of motility as compared to wild type strain was demonstrated (Fig. 3).

The introduction of wild-type $d n a J$ gene at low-copy plasmid led not only to the complementation of $\Delta d n a J$ defect but even to substantial enhancement of biofilm formation. It was proved that the phenotype of strains overexpressing DnaJ chaperone differed from wild-type strains e.g. they increased survival in the presence of bactericidal antibiotics and suppressed all known dnaJ cbpA djlA triple mutant phenotypes (Genevaux et al., 2007). However, the enhancement of biofilm formation is most likely due to the overexpression of $d n a J$, as indicated by other research referring to the altered phenotype of such strains.

It is well known that DnaJ is important for many cellular functions, such as protein release and transport (Mayhew and Hartl, 1996), membrane lipid composition (Sieńczyk et al., 2004) and cell division (McCarthy and Walker, 1994), to mention only a few. We have demonstrated that biofilm formation by E.coli is another function influenced by this chaperone.

\section{Literature}

Beloin C., A. Roux and J.-M. Ghigo. 2008. Escherichia coli biofilms. Curr. Topics Microbiol. Immunol. 322: 249-289.

Casadaban M. and S.S. Cohen. 1980. Analysis of gene control signals by DNA fusion and cloning in Escherichia coli. J. Molec. Biol. 138: 179-207.

Castanié-Cornet M.P., N. Bruel and P. Genevaux. 2014. Chaperone networking facilitates protein targeting to the bacterial cytoplasmic membrane. Biochim. Biophys. Acta 1843: 1442-1456. 
Cuéllar J., J. Perales-Calvo, A. Muga, J. M. Valpuesta and F. Moro. 2013. Structural insights into the chaperone activity of the $40-\mathrm{kDa}$ heat shock protein DnaJ: binding and remodeling of a native substrate. J. Biol. Chem. 288: 15065-15074.

de la Fuente-Núňnez C., F. Reffeuville, L. Fernández and R.E. Hancock. 2013. Bacterial biofilm development as a multicellular adaptation: antibiotic resistance and new therapeutic strategies. Curr. Opin. Microbiol. 16: 580-589.

Donlan R.M. and J.W. Costerton. 2002. Biofilms: survival mechanisms of clinically relevant microorganisms. Clin. Microbiol. Rev. 15: 167-193.

Dubern J.F., E.L. Lagendijk, B.J. Lugtenberg and G.V. Bloemberg. 2005. The heat shock genes $d n a K, d n a J$ and $g r p E$ are involved in regulation of putisolvin biosynthesis in Pseudomonas putida PCL1445. J. Bacteriol 187: 5967-5976.

Flemming H.-C. and J. Wingender. 2010. The biofilm matrix. Nat. Rev. Microbiol. 8: 623-633.

Genevaux P., C. Georgeopoulos and W.L. Kelly. 2007. The Hsp70 chaperone machines in Escherichia coli; a paradigm for the repartition of chaperone functions. Mol. Microbiol. 66: 840-857.

Hall M.P., M.G. Gruber, R.R. Hannah, M.L. Jennes-Clough and K.V. Wood. 1998. Stabilization of firefly luciferase using directed evolution. pp. 392-395. In: Roda A., M. Pazzagli, L.J. Kricka and P.E. Stanley (eds). Bioluminescence and Chemiluminescence, Perspectives for the 21st Century. John Wiley \& Sons, New York.

Hoiby N., T. Bjarnsholt, M. Givskov, S. Molin and O. Ciofu. 2010. Antibiotic resistance of bacterial biofilms. Int. J. Antimicrob. Agents 35: 322-332.

Karatan E. and P. Watnick. 2009. Signals, regulatory networks, and materials that build and break bacterial biofilms. Microbiol. Mol. Biol. Rev. 73: 310-347.

Lemos J.A., Y. Luzardo and R.A. Burne. 2007. Physiologic effects of forced down-regulation of $d n a K$ and groEL expression in Streptococcus mutants. J. Bacteriol. 189: 1582-1588.

Lippolis J.D., B.W. Brunelle, T.A. Reinhardt, R.E. Sacco, B.J. Nonnecke, B. Dogan, K. Simpson and Y.H. Schukken. 2014. Proteomic analysis reveals protein expression diffrences in Escherichia coli strains associated with persistent versus transient mastitis. J. Proteomics 108: 373-381.

Lundin A. and A. Thore. 1975. Analytical information obtained by evaluation of the time course of firefly bioluminescence in the assay of ATP. Anal. Biochem. 66: 47-63.

Mayhew M. and F.U. Hartl. 1996. Molecular chaperone proteins, pp. 217-261. In: Neidhard N.C., R. Curtiss III, J.L. Ingraham, E.C.C.
Lin, K.B. Low, B. Magasanik, W.S. Reznikoff, M. Riley, M. Schaechter and H.E. Umbarger (eds). Escherichia coli and Salmonella, Cellular and Molecular Biology. ASM Press, Washington, D.C.

McCarthy J. and G.C. Walker. 1994. DnaK mutants defective in ATPase activity are defective in negative regulation of the heat shock response: expression of the mutant DnaK proteins results in filamentation. J. Bacteriol. 76: 764-780.

McFarlane S. and J.F. Dillon. 2007. Microbial biofilms in the human gastrointestinal tract. J. Appl. Microbiol. 192: 1187-1196.

O'Toole G.A. and R. Kotler. 1998. Initiation of biofilm formation in Pseudomonas fluorescens WCS365 proceeds via multiple, convergent signaling pathways; a genetic analysis. Mol. Microbiol. 28 449-461.

Paciorek J., K. Kardyś, B. Łobacz and K.I. Wolska. 1997. Escherichia coli defects caused by null mutations in $d n a K$ and $d n a J$ genes. Acta Microbiol. Polon. 46: 7-17.

Raczkowska A., S. Karolina, M. Brzóstkowska, A. Lasińskaand K. Brzostek. 2011. Pleiotropic effects of a Yersinia enterocolitica $o m p R$ mutation on adherent-invasive abilities and biofilm formation. FEMS Microbiol. Lett. 321: 43-49.

Sieńczyk J., A. Skłodowska, A. Grudniak and K.I. Wolska. 2004 Influence of DnaK and DnaJ chaperones on Escherichia coli membrane lipid composition. Pol. J. Microbiol. 53: 121-123.

Singh V.K., M. Syring, A. Singh, K. Singhal, A. Dalecki and T. Johansson. 2012. An insight into the significance of DnaK heat shock system in Staphylococcus aureus. Int. J. Med. Microbiol. 302: 242-252.

Srinivasan S.R., A.T. Gilles, L. Chang, A.D. Thompson and J.E. Gestwicki. 2012. Molecular chaperones DnaK and DnaJ share predicted binding sites on most proteins in the E. coli proteome. Mol. Biosyst. 8: 2323-2333.

van der Veen S. and T. Abee. 2010. HrcA and DnaK are important for static and continuous-flow biofilm formation and disinfectant resistance in Listeria monocytogenes. Microbiology 156: 3782-3790.

Verstraeten N., K. Braeken, B. Debkumari, M. Fauvarat, J. Fransaer, J. Vermant and J. Michiels. 2008. Living on a surface: swarming and biofilm formation. Trends Microbiol. 16: 496-506.

Walsh P., D. Bursać, Y.C. Law, D. Cyr and T. Lithgow. 2004. The J-protein family: modulating protein assembly, disassembly and translocation. EMBO Rep. 5: 567-571.

Wolska K.I., E. Bugajska, D. Jurkiewicz, M. Kuć and A. Jóźwik. 2000. Antibiotic susceptibility of Escherichia coli dnaK and dnaJ mutants. Microb. Drug Res. 6: 119-126. 
